\title{
A Multiple L-Shaped Slot Loaded Antenna with Multiband Circularly Polarized for WLAN \& WiMAX Applications
}

\author{
Sanjeev Kumar, Durgesh Nandan, Amit Shivhare, Ravi kumar
}

\begin{abstract}
In this paper, a compact four asymmetric $L$ shaped slots loaded antenna has been designed for the wireless network \& WiMAX applications. The antenna consists of four asymmetrical L-shaped slots with an area of $94 \mathrm{~mm}^{2}, 66 \mathrm{~mm}^{2}, 44$ $\mathrm{mm}^{2} \& 28 \mathrm{~mm}^{2}$ respectively \& probe fed provides for the excitation to the antenna. The antenna can be operated between $2.6 \mathrm{GHz}$ to $5.4 \mathrm{GHz}$ frequency range. The proposed antenna resonant at three different frequencies as $2.95 \mathrm{GHz}, 4.85 \mathrm{GHz}$ \& $5.23 \mathrm{GHz} \&$ the return loss are $-16.5 \mathrm{~dB},-13.6 \mathrm{~dB} \&-14.6 \mathrm{~dB}$ respectively. It produces one linear polarization at $2.95 \mathrm{GHz}$ frequency \& two circular polarizations at frequencies $4.84 \mathrm{GHz}$ \& $5.21 \mathrm{GHz}$. The proposed antenna finds its application in WLAN (2.94-3.05) GHz, WiMAX (4.81-4.92) GHz \& IEEE $802.11 a(5.15-5.35) \mathrm{GHz}$. The proposed antenna simulation results show that good radiation pattern with multi frequency band in comparison of reported designs.
\end{abstract}

Keywords: Circularly Polarized (CP), microstrip antenna, multiband antenna, Wireless Area Network (WLAN), Worldwide Interpretability for Microwave Access (WiMAX), IEEE 802.11a.

\section{INTRODUCTION}

Microstrip antennas are versatile in terms bandwidth, polarization \& radiation pattern with conformable to planar \& no-planar surfaces. It can be designed for various applications such as handheld mobile, satellites, aircraft, etc. Today they are used for government \& commercial applications [1-2]. To facilitate human interaction, a new technology has been implemented such as WLAN \& system in modern technology. In order to achieve compactness in the antenna, many researchers try to compact patch sizes via various techniques like introducing several slots on the patch, meandering patch \& shorting pin between ground plane \& patch. In [3], a compact dual-band microstrip slot antenna is proposed in which pair of mirror image L-shape slots \& slits are etched on the patch resonator. A new dual band CP slot antenna designed inserted with metallic strip was introduced [4-5]. Dual band CP slot antenna is proposed by an asymmetrical slot $\&$ two different truncated corners [6].

Triple band antennas have been demonstrated by using single layer coax fed U-slot patch [7], a compact H-shaped

Revised Manuscript Received on August 14, 2019

Sanjeev Kumar ECE, Oriental Institute of Science \& Technology, Bhopal, Madhya Pradesh, India. ( Email : sanjeevjuet@gmail.com)

Dr. Durgesh Nandan, CL Educate Ltd, New Delhi, India. (Email : prof.durgeshnandan@gmail.com)

Amit Shivhare ECE, Jaypee University of Engineering \& Technology, Guna, Madhya Pradesh, India. (Email : amitshivhare@gmail.com)

Dr. Ravi Kumar ,( Email : ravi.kumar6@gmail.com) slot antenna [8], a hexagonal slot antenna with multi L-slits [9], two angular slots fed by an inverted h-shaped microstrip line [10]. Several multilayered stacked patch antennas are proposed for triple band operation [11-12]. Since CP antenna offers many advantages over linear polarization like high penetration \& ability of establishing a reliable signal link irrespective of the antenna orientation. Therefore, CP gives better connectivity with both mobile \& fixed devices [13-15].

Recently, a single layer triple band antenna with two linear polarization (LP) \& one circular polarization (CP) \& overall dimension of antenna is $60 \times 60 \times 1.5 \mathrm{~mm}^{3}[16]$. In other reports, triple band multi polarized planar antenna for WLAN/WiMAX application with two LP \& one CP \& overall dimension of antenna is $55 \times 55 \times 3.175 \mathrm{~mm}^{3}$ [17].

In this research article, a multi polarized triple band patch antenna for WLAN/WiMAX application is proposed. It consists of four asymmetrical L-shaped slot etching on the patch. According to tune the arms of L-shaped slot, the location, the gap between the slots $\&$ size of the arms of slot $\&$ three distinct operating frequencies can be produced respectively. Overall proposed antenna dimension is $34 \times 31 \times 1.59 \mathrm{~mm}^{3}$. Simulated results show that the proposed antenna can effectively cover three separated $\mathrm{S}_{11}$ bandwidth of $52 \mathrm{MHz}(2.995-2.946 \mathrm{GHz}), 62 \mathrm{MHz}(4.8872-4.8251$ $\mathrm{GHz}) \& 86 \mathrm{MHz}(5.2760-5.1906 \mathrm{GHz})$ with one LP \& two CP bandwidth $48 \mathrm{MHz}(4.8699-4.8219 \mathrm{GHz})$ \& $36 \mathrm{MHz}$ (5.2013-5.2373 GHz), which satisfy the requirement of WLAN, WiMAX \& IEEE 802.11a bands.

\section{ANTENNA STRUCTURE \& DESIGN}

Proposed antenna with single layer structure has be shown in Fig. 1. It is designed with coaxial feed on FR-4 substrate having relative permittivity 4.4 , thickness of the substrate $1.59 \mathrm{~mm} \&$ loss tangent of the FR-4 substrate material is 0.02 . Dimension of patch has been calculated by using equation 1-4 as given in [1]. Width of the patch antenna is

$$
w=\frac{1}{2 f_{r \sqrt{\mu_{0} \varepsilon^{\circ}}}} \sqrt{\frac{2}{\varepsilon_{r}+1}}
$$

$\&$ the effective dielectric constant of substrate is computed by using equation as 


$$
\varepsilon_{e f f}=\frac{\varepsilon_{r+1}}{2}+\frac{\varepsilon_{r-1}}{2}\left[1+12 \frac{h}{w}\right]^{-\frac{1}{2}}
$$

$\Delta \mathrm{L}$ increases in length due to fringing effect is given by

$$
\Delta L=0.412 h \frac{\left(\varepsilon_{\text {eff }}+0.3\right)\left(\frac{W}{h}+0.264\right)}{\left(\varepsilon_{\text {eff }}-0.258\right)\left(\frac{W}{h}+0.8\right)}
$$

Then the effective length of patch is computed by

$$
L_{e f f}=\frac{1}{2 f_{r} \sqrt{\varepsilon_{\text {eff }}} \sqrt{\mu_{o} \varepsilon_{o}}}-2 \Delta L
$$

Where $f_{r}$ is lowest resonance frequency. Overall size of antenna is $34 \times 31 \times 1.59 \mathrm{~mm}^{3}$. All the dimensions of the proposed antenna has been shown in Table 1. In Fig. $1 l_{4} \& w_{4}$ are the arms of the first L-slot, $l_{3} \& w_{3}$ are the arms of second L-slot, $l_{2} \& w_{2}$ are the arms of third L-slot $\& l_{l} \& w_{l}$ are the arms of fourth L-slot respectively. The gap between two consecutive slots is $w_{d} \& l_{x} \& l_{y}$ are distance from edge of the patch.

Table 1: Antenna dimensions (in mm)

\begin{tabular}{|c|c|c|c|c|c|c|}
\hline$L$ & $W$ & $l_{1}$ & $l_{2}$ & $l_{3}$ & $l_{4}$ & $w_{1}$ \\
\hline 27 & 30 & 17 & 11 & 7 & 5 & 21. \\
\hline$w_{2}$ & $w_{3}$ & $w_{4}$ & $w_{s}$ & $w$ & $l_{x}$ & $l_{y}$ \\
\hline 16. & 11. & 6.5 & 3 & 2 & 8.5 & 8 \\
\hline
\end{tabular}

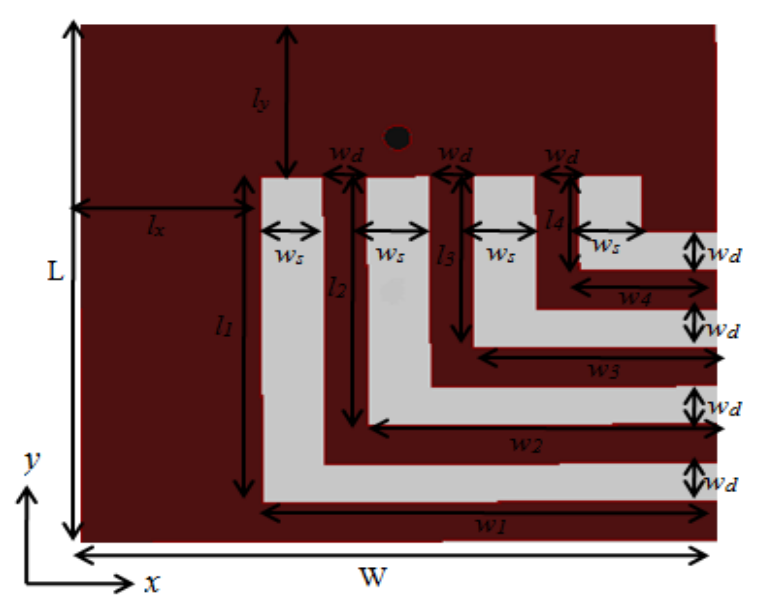

Fig. 1. Proposed antenna geometry.

\section{PARAMETRIC STUDY OF PROPOSED ANTENNA}

The proposed recieving telegram is planned on $\mathrm{Fr}$ quaternary substratum having piece measurement $30 \times 27$ $\mathrm{mm} 2$ and substrate size of $34 \times 3$ one mm2.Francium -4 with a dielectric steady of 4.4 is fiberglass material with epoxy sap fastener that offers minimal effort yet with high misfortune so it is utilized less for return over a couple of Gigacycle . 3D-Electromagnetic test system Ansoft HFSS v1 five has been utilized to structure the wireless wire. Exceptional blends of various L-SHAPE first step are stacked in the radio wire. The structure of reception apparatus from single L-molded opening to four L-formed distance as outlined in Fig.1. Unity L-molded opening gives no any echo recurrence however when including number of space, the quantity of working striation additionally increment. When including two L-formed scuttle give one reverberation recurrence at 5.16 Gigacycle and including three-base hit L-molded outer space give look-alike isthmus of reverberation recurrence at $3.00 \mathrm{GHz}$ and $5.05 \mathrm{GHz}$. The triple band of reverberation frequencies are accomplished through the four L-material body distance are at $2.95 \mathrm{GHz}$, $4.85 \mathrm{GHz}$ and $5.23 \mathrm{GHz}$. All L-formed space are topsyturvy in nature. These unbalanced outer space brand workable for the excitation of two symmetrical way with equivalent in adequacy because of this creates roundabout polarization. The arms of L-formed openings are unbalanced in nature and cut length along the $\mathrm{x}$-hub (w1, w2, w3 \& w4) and y-pin (11, 12, 13\& 14) course of the customary mending wind the energized fix surface current densities of the two symmetrical mode prompting a roundabout polarization with multiband in arrangement. For the long time of round polarization radioactivity design, the length and width of the L-material body opening have been upgraded just as streamline its situation of the spaces along the $\mathrm{x}$ and $\mathrm{y}$-pivot. To accomplish the proposed radio wire, well ordered Lshape spaces carved on the highest point of the fix.

When issue of slot $\mathrm{s}$ are increasing from single to many, in this case, the atomic number 7quint onance oftenness is shifted towards the lower side due to the coupling of the electric field \& increase in the electric length of the bandage . The simulated restoration red public presentation of proposed antenna with the four L-shape slot.The critical intent parameters are based on arm's length \& width of Lshaped slot $\&$ the interruption between the consecutive Lslot $\&$ also temporary hookup size of it influence the characteristics of the antenna. The location for the probe feed is on the y-axis at VII .quintuplet millimeter from the patch center field. The simulated surface electric current dispersion at quaternity $.84 \mathrm{GHz}$ is shown in Libyan Islamic Group. 3 which appearance the circular polarization wave of proposed antenna. The surface current dispersion on the patch at different phase angle is shown in Fig. 3(a)-(d). In this Fig., it shows that current on the patch radiator travels in the anti-clockwise direction, which resolution $\mathrm{s}$ in exciting a right-handed circular polarization (RHCP) radiation. Similarly, in Fig. 4 shows the surface current distribution at $5.21 \mathrm{GHz}$ and it is also RHCP. In Fig. 5 shown, the mutant of S11 with oftenness for different half a dozen senses of value of donkeywork aerowoodworking plane length has been optimized from $29 \mathrm{~mm}$ to $35 \mathrm{~mm}$ to obtained best result at $31 \mathrm{~mm}$. Therefore, the ground plane size of $31 \mathrm{~mm}$ is selected as the optimum size for better result for multiband operation. In Fig. 6 the variation of return going with frequency for different values of patch size has been shown. Patch size has been optimized from $26 \mathrm{~mm}$ to 29 $\mathrm{mm}$, it has been observed that when patch size increases there is a shift in ringing frequency toward lower frequency but we got best result at $27 \mathrm{~mm}$ patch size. The return loss variation with frequency for different values of crack between consecutive vertical weapon is shown in Fig. 7 With increasing the gap of vertical arm, resonance frequency of the antenna drop-off. The best result found that 
at $2 \mathrm{~mm}$ gap between them \& Fig. 8 shows simulation result. It indicated that a dual lot handbill polarization operation with good axial ratio bandwidth within the operating bandwidth of the antenna. For the lower band about $48 \mathrm{MHz}$ of 3dubnium axial ratio bandwidth is from 4.86ennead 9 to $4.8219 \mathrm{GHz}$, while for the upper berth band a $36 \mathrm{MHz}$ bandwidth is observed between $5.2013 \mathrm{GHz} \& 5.2373 \mathrm{GHz}$. In Fig. 9 shows the maximum gain of the proposed antenna is $3.4 \mathrm{~dB}$.

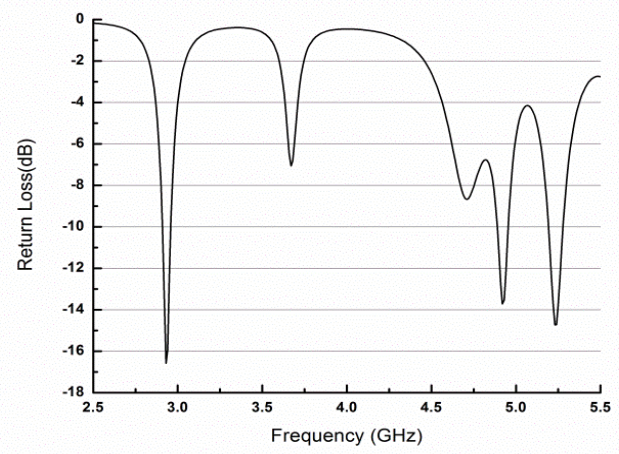

Fig. 2. (a) Simulated return loss Vs frequency of proposed patch antenna.
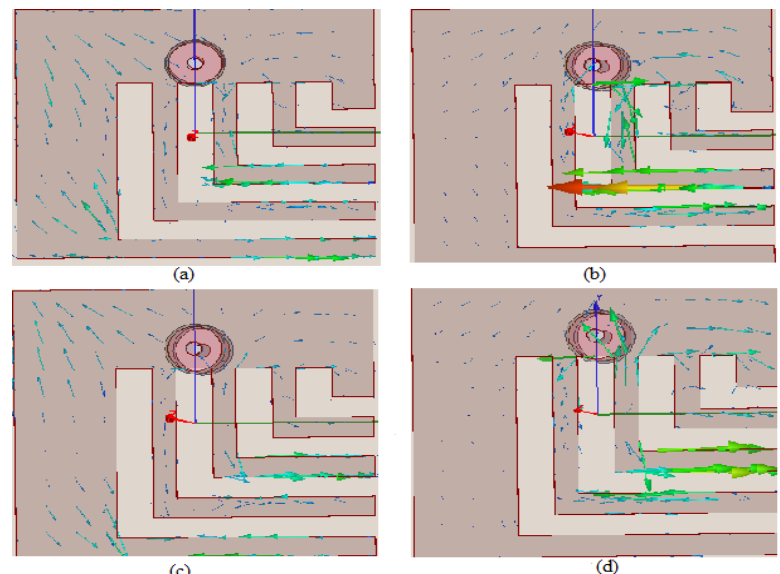

Fig. 3. HFSS simulated surface current distribution of the proposed antenna at $4.84 \mathrm{GHz}$. (a ) $0^{\circ}$ (b) $90^{\circ}$ (c) $180^{\circ}$ (d) $270^{\circ}$
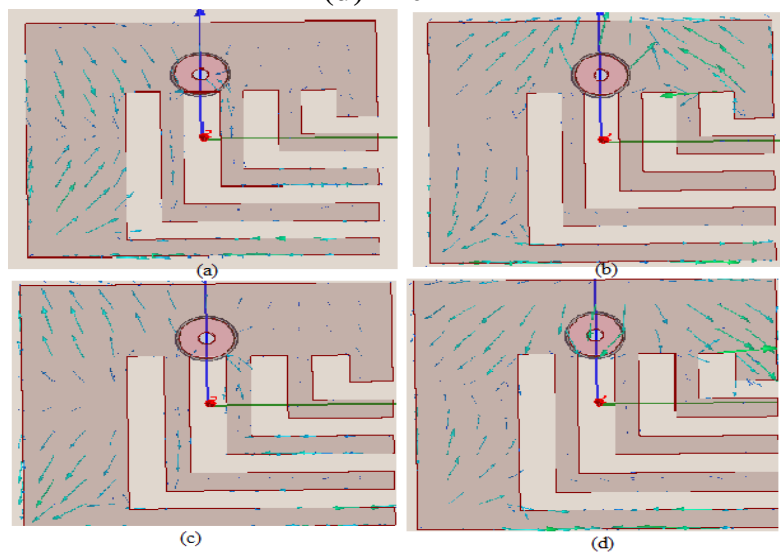

Fig. 4. HFSS simulated surface current distribution of the proposed antenna at $5.21 \mathrm{GHz}(\mathrm{a}) 0^{\circ}$ (b) $90^{\circ}$ (c) $180^{\circ}$ (d) $270^{\circ}$

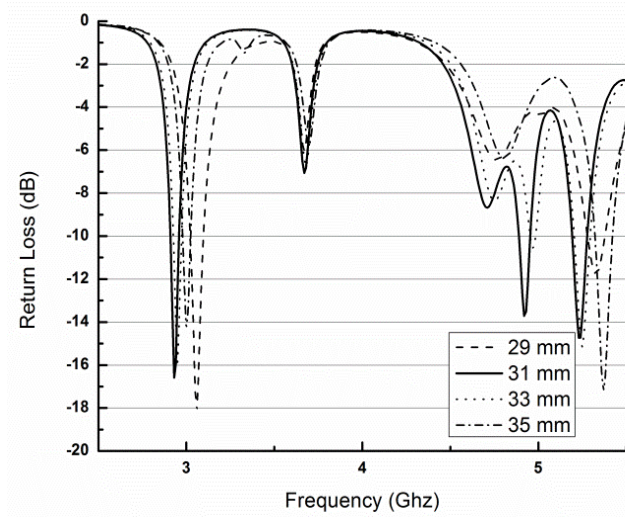

Fig. 5. Simulated return loss Vs frequency for various ground plane size.

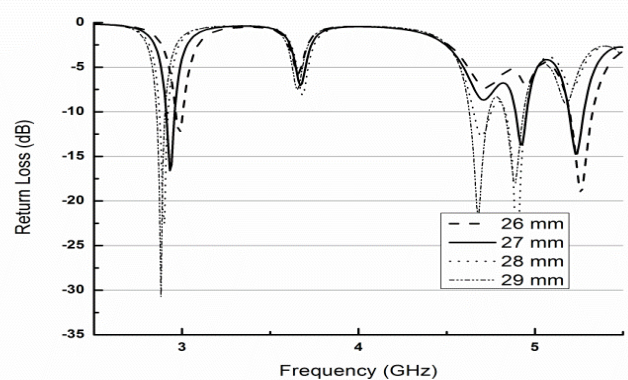

Fig. 6. Simulated return loss Vs frequency for various patch size.

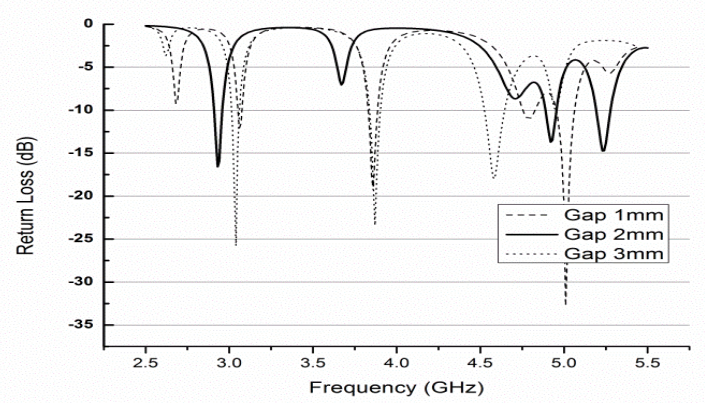

Fig. 7. Simulated return loss Vs frequency for various gap between the slot

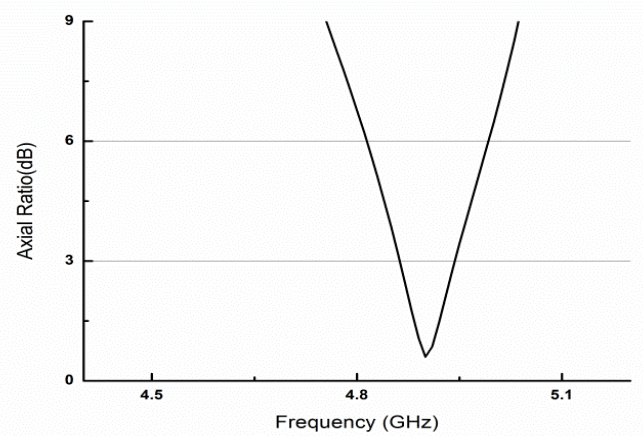

(a) 


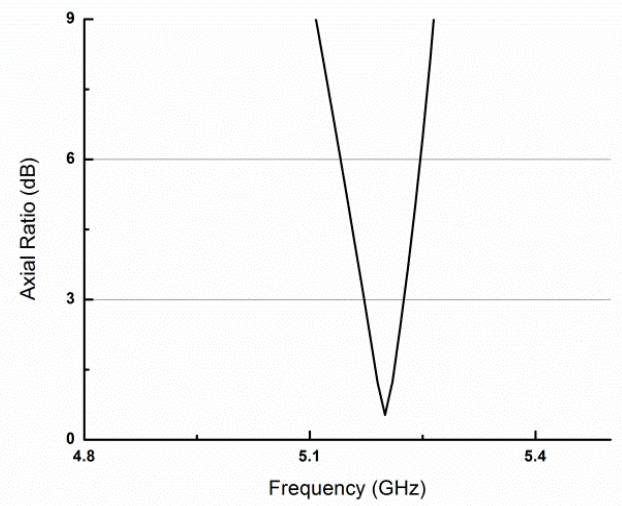

(b)

Fig. 8. Simulated axial ratio Vs frequency of proposed antenna (a) AR at 4.84 Ghz (b) AR at 5.21 GHz.

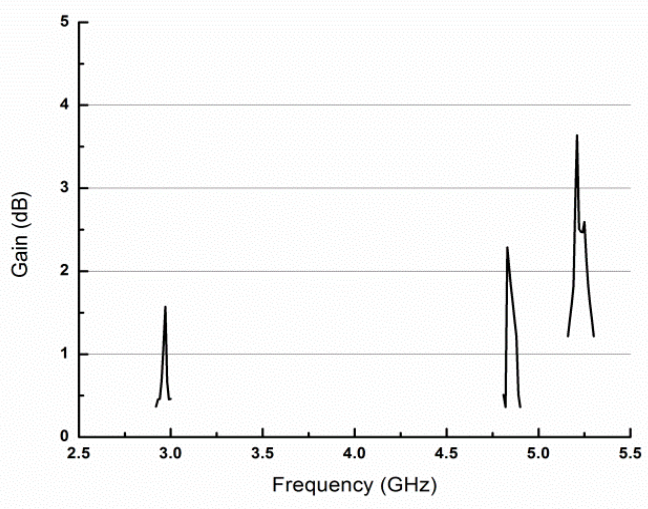

Fig. 9. Simulated gain of proposed antenna

\section{RESULTS \& DISCUSSION}

The proposed A Multiple L-Shaped Slot Loaded Antenna with Multiband Circularly Polarized for WLAN \& WiMAX Application has been optimed. Accroding to the above analysis, a triple band with dual circular polarization MSA is designed by using of the 3-D EMT simulator HFSS. In Fig. 2 shows the triple band of operation at different frequencies $2.59,4.85 \& 5.23 \mathrm{GHz}$ respecitively. In Fig. 8 shows the dual band CP operation at $4.84 \mathrm{GHz} \& 5.21 \mathrm{GHz}$. As can be seen from Fig. (a)-(b), shows the surface current distribution which shows the right hand circular polarization (RHCP). In Fig. 9 shows the maximum gain of proposed antenna is $3.4 \mathrm{~dB}$. Overall the proposed result is found better than the results shown for the stuructures proposed in [3], [6], [13], [15], [16] \& [17].

Table 2: Comparison table of compact circularly polarized microstrip antenna

\begin{tabular}{|l|l|l|l|l|}
\hline Antenna & Description & $\begin{array}{l}\text { Number } \\
\text { of } \\
\text { resonant } \\
\text { frequency } \\
\text { band }\end{array}$ & $\begin{array}{l}\text { Num } \\
\text { ber } \\
\text { of CP } \\
\text { band }\end{array}$ & $\begin{array}{l}\text { Overall } \\
\text { antenna } \\
\text { size }\left(\mathbf{m m}^{3}\right)\end{array}$ \\
\hline$[16]$ & $\begin{array}{l}\text { Design of U- } \\
\text { shaped antenna }\end{array}$ & Two & Zero & $\begin{array}{l}44 \times 40 \times 1 . \\
6\end{array}$ \\
\hline$[3]$ & $\begin{array}{l}\text { Dual band } \\
\text { miniaturized } \\
\text { MSA }\end{array}$ & Two & Zero & $\begin{array}{l}40 \times 20 \times 1 . \\
6\end{array}$ \\
\hline
\end{tabular}

\begin{tabular}{|l|l|l|l|l|}
\hline$[6]$ & $\begin{array}{l}\text { A dual band } \\
\text { CP MSA }\end{array}$ & Two & Two & $\begin{array}{l}55 \times 55 \times 1 . \\
6\end{array}$ \\
\hline$[13]$ & $\begin{array}{l}\text { Multiband } \\
\text { MSA }\end{array}$ & Three & One & $\begin{array}{l}60 \times 50 \times 1 . \\
5\end{array}$ \\
\hline$[17]$ & $\begin{array}{l}\text { Multiband } \\
\text { MSA with } \\
\text { CP }\end{array}$ & Three & One & $\begin{array}{l}55 \times 55 \times 1 . \\
56\end{array}$ \\
\hline$[15]$ & $\begin{array}{l}\text { Multiband } \\
\text { multi } \\
\text { polarized } \\
\text { MSA }\end{array}$ & Three & One & $\begin{array}{l}55 \times 50 \times 3 . \\
175\end{array}$ \\
& $\begin{array}{l}\text { A multiple } \\
\text { L-shaped } \\
\text { MSA }\end{array}$ & Three & Two & $\begin{array}{l}34 \times 31 \times 1 . \\
59 \\
\text { sed }\end{array}$ \\
\hline
\end{tabular}

The comparative analysis of proposed with other existing antenna has been shown in Table $2 \&$ proposed antenna gives better results in terms of size, bandwidth etc.

\section{CONCLUSION}

The multiband, single feed, single layer, circularly polarized, low profile \& low cost MSA is simulated. The proposed antenna with an overall size is $34 \times 31 \times 1.59$ $\mathrm{mm}^{3}$. The use of the four asymmetrical L-shaped slot generates the circular polarization \& 3-dB axial ratio bandwidth is $48 \mathrm{MHz} \& 36 \mathrm{MHz}$. The triple band behavior is obtained due to the etching L-shaped slots within a patch \& achieved bandwidth of $52.0 \mathrm{MHz}, 62 \mathrm{MHz} \& 86 \mathrm{MHz}$ respectively. The proposed antenna can be used for WLAN, WiMAX \& IEEE 802.11a applications.

\section{REFERENCES}

1. C.A. Balanis, Antenna Theroy: Analysis and Design, $3^{\text {rd }}$ ed., New York: John willey \& sons , 2005.

2. S. Kumar, R. Kumar and R. K. Vishwakarma, "A circular disc microstrip antenna with dual notch band for GSM/Bluetooth and extended UWB application," International Journal of Engineering \& Technology, vol. 7, pp. 11-18, 2018

3. M. S. M. Ali, S. K. A. Rahim, M. I. Sabran, M. Abedian, A. Eteng and M. T. Islam, "Dual band miniaturized microstrip slot antenna for WLAN applications", Microwave and Optical Technology Letters, vol. 58, pp. 1358-1362, 2016.

4. G. Zaho, L. N. Chen and Y. C. Jiao, "Design of a broadband dual circularly polarized square slot antenna", Microwave and Optical Tecnology Letters, vol. 50, pp. 2639-2642, 2008.

5. K. P. Yang and K. L. Wong, "Dual band circulaly polarized square microstrip antenna", IEEE Transactions on Antennas and Propagation, vol. 49, pp. 377-382, 2001.

6. S. M. Moghabaei et al., "Adual band circularrly polarized patch antenna with a novel asymmetric slot for WiMAX application", Radioengineering, vol. 22, pp. 291-295, 2013.

7. W. C. Mok, S.H. Wong,K. M. Luk, and K. F. Lee, "Single layer single patch dual band and triple band patch antenna", IEEE Transactions on Antennas and Propagation, vol. 61, pp. 4341-4345, 2013.

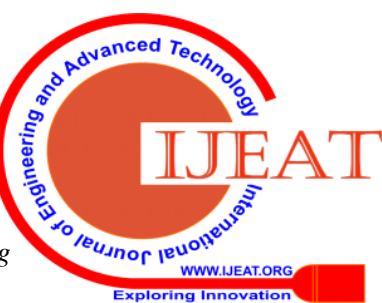


8. T. H. Chang and J. F. Kiang, "Compact multi band Hshaped slot antenna", IEEE Transactions on Antennas and Propagation, vol. 61, pp. 4345-4349, 2013.

9. J. G. Baek and K. C. Hwang, "Triple band unidirectional circulary polarized hexagonal slot antenna with multiple L-shaped slits," IEEE Transactions on Antennas and Propagation, vol. 61, pp. 4831-4835, 2013.

10. L. Wang, Y. X. Guo and W. X. Sheng, "A single feed triband circularly polarized dual annular slot antenna for wireless applications," Journal of Electromagnetic Waves and Applications, vol. 26, pp. 1389-1396, 2012.

11. O. P. Falade, Y. Gao, X. Chen and C. Parini, "Stacked patch dual polarized antenna for triple band handheld terminals," IEEE Antennas Wireless and Propagation Letters, vol. 12, pp. 202-205, 2013.

12. C. Wang and B. J. Hu, "A triple band circularly polarized patch antenna with multilayer and spiral slot lefthanded structures," Journal of Electromagnetic Waves and Applications, vol. 26, pp. 623-632,2012.

13. P. K. Singh, I. Sharma, G. Singh and H. S. Dhanny, "Multiband microtsrip antenna with circular polarization for wireless local area network," IEEE coferenece on Innovation and Challenges in Cyber Security (ICICCSINBUsh), India. pp. 319-322, 2016.

14. S. Kumar et al., "Slotted circularly polarized microstrip antenna for RFID application," Radioenginering, vol 26 , pp. 1025-1032, 2017.

15. S. R. Rama, D. Vakula and N.V. S.N. Sarma, "Multiband multipolarized planar antenna for WLAN/WiMAX appilcations," IEEE conference on International Review Progress on Applied Computational Electromagnetics, USA, pp. 1-2, 2015.

16. B. Roy, U. Chakraborty, S. K. Chowdhury and A. K. Bhattacharjee, "Design of U-shaped antenna using different substrate with enhanced bandwidth for WLAN/WiMAX application," Microwave and Optical Technology Letters, vol. 58, pp. 959-963, 2016.

17. I. Sharma et al., "Multiband microtsrip antenna with circular polarization for wireless communication," India,IEEE conference on Futuristic Trends on Computational Analysis and Knowledge Management (ABLAZE), pp. 577-580, 2015.

\section{AUTHORS PROFILE}

Sanjeev Kumar ECE, Oriental Institute of Science \& Technology, Bhopal, India ,Email ID: sanjeevjuet@ gmail.com

Dr. Durgesh Nandan, CL Educate Ltd, New Delhi, India, Email ID: prof.durgeshnandan@gmail.com

Amit Shivhare ECE, Jaypee University of Engineering \& Technology, Guna, India, Email ID: amitshivhare@gmail.com

Dr. Ravi Kumar ,Email ID: ravi.kumar6@gmail.com 